\title{
Embracing the variety of sustainable business models: A prolific field of research and a future research agenda
}

\author{
Nikolay Dentchev ${ }^{\mathrm{a}, ~ *}$, Romana Rauter ${ }^{\mathrm{b}}$, Lára Jóhannsdóttir ${ }^{\mathrm{c}}$, Yuliya Snihur ${ }^{\mathrm{d}}$, \\ Michele Rosano ${ }^{\mathrm{e}}$, Rupert Baumgartner ${ }^{\mathrm{b}}$, Timo Nyberg ${ }^{\mathrm{g}}$, Xingfu Tang ${ }^{\mathrm{h}}$, Bart van Hoof ${ }^{\mathrm{i}}$, \\ Jan Jonker ${ }^{\mathrm{j}}$ \\ ${ }^{a}$ Vrije Universiteit Brussel and KULeuven, Pleinlaan 2, 1050, Brussels, Belgium \\ ${ }^{\mathrm{b}}$ University of Graz, Austria \\ ${ }^{\mathrm{c}}$ University of Iceland, Iceland \\ d Toulouse Business School, France \\ e Curtin University, Australia \\ ${ }^{g}$ Aalto University, Finland \\ h Fudan University, China \\ i Universidad de los Andes, Colombia \\ ${ }^{\mathrm{j}}$ Radboud University Nijmegen, The Netherlands
}

\section{A R T I C L E I N F O}

\section{Article history:}

Received 27 February 2018

Accepted 19 May 2018

Available online 22 May 2018

\section{Keywords:}

Sustainable business models

Corporate sustainability

Sustainability management

Social entrepreneurship

Circular economy

\begin{abstract}
A B S T R A C T
Investigating the benefits of sustainable business models for our societies is an important and timely topic. This Special Volume contributes to current research by exploring a variety of sustainable models in use around the world. The accepted articles provide an overview of the various organizational forms, management mechanisms, sustainability solutions, challenges, theoretical lenses and empirical evidence, i.e. fundamental elements in the study of sustainable business models. In this introductory paper, the thirty-seven articles included in this Special Volume are presented, organized in four approaches to sustainable business models: $1 /$ the generalist approach, $2 /$ the technology-based approach, $3 /$ the entrepreneurship and innovation approach and 4/the behavioral approach. In conclusion, avenues for future research are formulated, with a call for solid theory building, more sophisticated research methods, focus on the interplay of sustainable with existing conventional business models, and systemic consideration of the role of governments in advancing sustainable business models.
\end{abstract}

๑) 2018 Elsevier Ltd. All rights reserved.

\section{Introduction}

Research on sustainable business models (SBM) is a prolific field of interest. At first glance, it seems that it is simply associated with the diffusion of business model thinking and related tools (Osterwalder and Pigneur, 2010) in an effort to resolve the sustainability challenges of our planet (Brundtland, 1987). Yet a closer look at the heart of SBM scholarship reveals a fundamental focus on why and how organizations respond to sustainability issues (Bansal, 2003) by changing parts of their existing business models or developing completely new ones. An organizational lens on business model development in the context of sustainability

\footnotetext{
* Corresponding author.

E-mail address: nikolay.dentchev@vub.be (N. Dentchev).
}

reaches beyond typical business model ontology, and has the potential to enhance the existing understanding of various organizational forms that could help resolving current sustainability issues. With this potential in mind, Dentchev et al. (2016) called for a Special Volume (SV) in the Journal of Cleaner Production.

SBMs are defined by Schaltegger et al. (2016a, p. 6) as helpful tools for "describing, analyzing, managing, and communicating (i) a company's sustainable value proposition to its customers, and all other stakeholders, (ii) how it creates and delivers this value, (iii) and how it captures economic value while maintaining or regenerating natural, social, and economic capital beyond its organizational boundaries." Embracing the variety of SBMs is not only an important and timely topic, but it also helps to review the boundaries in the field and synthesize our current knowledge. Boundaries exist in terms of organizational forms, management mechanisms, potential sustainability solutions, challenges related 
to the practical application of SBM and empirical evidence as well as theoretical lenses on SBM. We thus agree with the argument of Schaltegger et al. (2016b, p. 265) that the "types of organizations, niche market players and mass market incumbents, all have different business models [...], different challenges in developing and establishing them." In this context, the papers in this SV build on fertile discussion of SBM characteristics and archetypes (Bocken et al., 2014; Stubbs and Cocklin, 2008), and provide further details of the managerial and policy implications of SBMs. The discussions in the field are aided by the contributions of numerous special issues on SBMs during the last couple of years: Arevalo et al. (2011), Boons et al. (2013), Haigh et al. (2015), Schaltegger et al. (2016), and Svensson and Wagner (2011). Based on the discussions in previous special issues and this current volume, we note that SBM scholarship is developed by a dynamic community of scholars across the world, who are committed to accelerating our knowledge on the transition towards sustainable societies.

However, SBMs are not without criticism as the concept itself has not been sufficiently clarified and the development of SBM theory is still in its infancy. There is a need for accumulating empirical evidence regarding SBMs, which could enhance the knowledge of both researchers and practitioners. This SV is only one step in this process, and provides valuable insights to SBM scholars, and could also of interest to scholars in sustainability management, corporate sustainability, circular economy, business model thinking, strategic management, innovation management, and social entrepreneurship. The thirty-seven papers published in this SV provide a rich set of theoretical insights, and draw on evidence from a variety of SBMs across multiple industries and countries. In addition, the ideas presented in this SV allow for practical implications for managers, consultants, and policy makers, who are dedicated to the creation and implementation of SBMs in distinct contexts.

The remainder of this article is structured as follows. In section 2 the main ideas of the respective papers published in this SV are presented and discussed, summarizing their theoretical lenses (see Table 1) and research method (see Table 2). Based on the underlying study focus, the articles are summarized following their focal point of research into four topics: 1) generalist approach, 2) technology-centered approach, 3) entrepreneurship and innovation-centered approach and, 4) behavioral approach. Finally, avenues for future research in the SBM field are presented in section 3, calling for further research on 1) SBM conceptualizations, 2) stronger and more cumulative theoretical development, 3) more sophisticated empirical methods, 4) the role of government in SBM development across different national contexts, 5) the interaction between existing business models and SBMs in one sector or even one company, and 6) the creation of dialogue and intersections with other research communities, such as "traditional" business model researchers, scholars of innovation, and the entrepreneurship community.

\section{Overview of papers published in this Special Volume}

This SV comprises thirty-seven papers of one-hundred-andeight authors from twenty-three countries (Australia, Australia, Belgium, Brazil, Canada, China, Denmark, Finland, Germany, Hong Kong, Iceland, Ireland, Italy, Lebanon, Mexico, Portugal, Slovenia, Spain, Sweden, The Netherlands, United Arab Emirates, United Kingdom, United States of America). The papers encompass studies from eleven different sectors, i.e. apparel, banking, education, energy, fashion, food and beverage, health care, housing, ICT, insurance, recycling, waste management. The authors used as many as twenty-three different theoretical lenses in their studies (cf. Table 1) In the following, the papers are grouped alongside the aforementioned four SBM approaches.

This SV comprises a set of conceptual and empirical research studies, not surprisingly dominated by case studies that often enable researchers to gain insights during early theory development stages, particularly useful in the context of grand challenges and complex issues such as sustainability-related problems our society is facing (Eisenhardt et al., 2016). Taken together, the papers provide solid contextual background (cf. case and field studies), apply mixed-method designs, yet some also use quantitative approaches like surveys, experiments, and simulations. Table 2 provides a summarizing overview with regard to the study focus, SBM type, and follows Scandura and Williams (2000) in presenting the research methods used in the papers published in this SV.

\subsection{Topic 1: the generalist approach to sustainale business models}

In this first topical area, authors have taken a generalist approach to SBMs (11 papers). The core topic of papers is either the review of existing studies or the empirical exploration of SBMs, new tools for mapping SBMs or SBM archetypes, and the examination of more specific SBMs targeting the base of the pyramid. These papers use a variety of perspectives, such as a novel focus on value transfer (Brehmer et al., 2018), transition theory (Bidmon and Knab, 2018), or the more traditional resource-dependence and network theory (Rossignoli and Lionzo, 2018) to shed light on SBMs and their features. These papers contribute to a general discussion about what SBMs are, what is currently known about SBMs, and how SBMs could or even should be studied and managed. Whereas Lüdeke-Freund and Dembek (2017) provide details about the state of the art of the SBM field, other studies here develop new theoretical and practical understandings of SBM types, roles, and scalability in a variety of contexts, and offer suggestions about how

Table 1

Theoretical lenses used in the papers published in this Special Volume.

\begin{tabular}{|c|c|c|}
\hline & Theoretical Lens & Author(s) \\
\hline 1 & Boundary-spanning perspective & Brehmer et al. (2018) \\
\hline 21 & Business model innovation & Olofsson et al. (2018) \\
\hline 3 & Change management & Long et al. (2018) \\
\hline 4 & Collective action theory & Gallo et al. (2018) \\
\hline 5 & Contingency theory & Maletič et al. (2018) \\
\hline 61 & Design thinking & Kozlowski et al. (2018) \\
\hline 7 & Entrepreneurial ecosystems & Neumeyer and Santos (2018) \\
\hline 8 & Hybrid organizations & $\begin{array}{l}\text { Davies and Chambers (2018); } \\
\text { Siegner et al. (2018) }\end{array}$ \\
\hline 9 & Information asymmetry & Plank and Teichmann (2018) \\
\hline 10 & Institutional theory & Stål and Corvellec (2018) \\
\hline 11 & Lean Thinking & Caldera et al. (2017) \\
\hline 12 & Life cycle assessment & Ribeiro et al. (2018) \\
\hline 13 & Network theory & $\begin{array}{l}\text { Neumeyer and Santos (2018); Oskam } \\
\text { et al. (2018); Rossignoli and Lionzo } \\
\text { (2018) }\end{array}$ \\
\hline 14 & Resource dependence theory & Rossignoli and Lionzo (2018) \\
\hline 15 & Resource mobilization theory & McDermott et al. (2018) \\
\hline 16 & Schwartz Personal Values & Piscicelli et al. (Z018) \\
\hline 17 & $\begin{array}{l}\text { Stevenson (1983) multilevel } \\
\text { approach to entrepreneurial } \\
\text { management }\end{array}$ & Fellnhofer (2017) \\
\hline 18 & Strategic Management & Johannsdottir and McInerney (2018) \\
\hline 19 & System dynamics & Chen et al. (2018) \\
\hline 20 & Technology acceptance model & Kokkonen and Ojanen (2018) \\
\hline 21 & Theory of Planned Behavior & $\begin{array}{l}\text { Wesselink et al. (2017); Kokkonen and } \\
\text { Ojanen (2018) }\end{array}$ \\
\hline 22 & Transition theory & Bidmon and Knab (2018) \\
\hline 23 & User-centered design & Tolkamp et al. (2018) \\
\hline
\end{tabular}

Note: Since papers were assigned to different volumes as soon as they were accepted, the year of publications varies. All papers remain pooled together online as a virtual special issue. 
Table 2

Study focus, SBM type, and research method used in papers included in this SV.

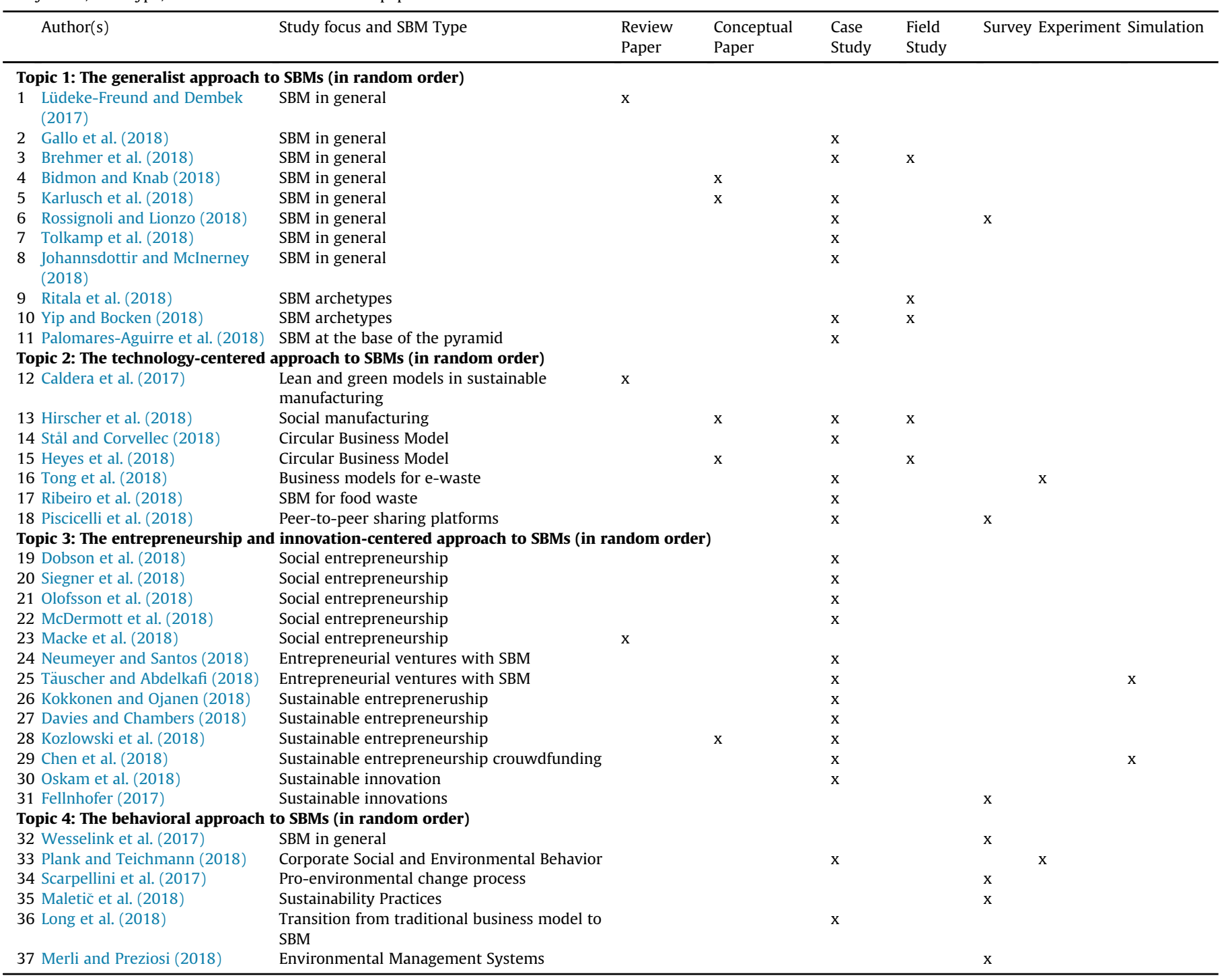

SBMs could be developed within organizations. The papers of Ritala et al. (2018) and Yip and Bocken (2018) extend our knowledge of SBM architypes (Bocken et al., 2014). Moreover, the importance of specific context is noted in SBM studies. Here, it is not only refered to the sector of activity, but also the economic development of countries. In this sense, Palomares-Aguirre et al. (2018) discuss the implementation of SBMs in the base of the pyramid contexts (Kolk et al., 2014; Prahalad and Hart, 1999). In these contexts, the authors argue in favor of the government support in line with Albareda et al. (2007), while some discussions in sustainability advocate for the principle of voluntarism, i.e. companies to decide upon their discretion which initiatives to take beyond formal regulation in support of sustainability (Carroll, 1979). Karlusch et al. (2018) contribute to another relatively absent discussion in SBMs, i.e. how to teach them at university. While sustainability education is an established stream, the scholarly discussion on SBM education can be further elaborated. Below, each paper's main ideas are presented each paper's main ideas.

Lüdeke-Freund and Dembek (2017) asked the ultimate question for the SBM scholarship, i.e. whether SBM research is worthy of being referred to as an emergent field of research or if it should be considered instead as a subfield of an already established one. Their analysis is based on a review of recent developments in SBM scholarship, practice and policy making, and confirmed that SBM is as an emerging field. This paper can serve as a guide to recent developments in the SBM field of research, as well as to its positioning toward other related fields.

Gallo et al. (2018) advance the knowledge on SBM with a new category called "associative sustainable business models". This novel category asserts the importance of associative behaviors including partnerships, networking and collaboration. The contribution of this paper is rooted in four case studies from the chocolate bar industry.

Brehmer et al. (2018) took a boundary-spanning perspective on SBMs. Based on a qualitative research that studied sixty-four organizations in the Netherlands with innovative SBMs, the researchers studied the content, structure and the governance of these SBMs. This paper provides a detailed and alternative perspective on constructivist, component-based, and design-based views of business modeling. One of the author's main conclusions is that the "imbalance of value exchanges is compensated for elsewhere in the business model" (Brehmer et al., 2018, p. 4514). 
Bidmon and Knab (2018) used a transition theory lens to propose a conceptual contribution to what they refer to as the three roles of SBMs. They present the roles of SBMs as (i) part of sociotechnical regime, (ii) intermediates between the technological niche and the socio-technical regime, and (iii) non-technological niche innovation. Their conceptual ideas are illustrated with cases from the German energy sector.

Karlusch et al. (2018) used a case study of Vienna University, Austria, to present the development of a course on sustainable business models. The details of course development may possibly be beneficial and inspirational for those in academia and higher education who are interested in SBMs.

Rossignoli and Lionzo (2018) have built upon the resource dependence theory and network theory to study Green Energy Networks in Italy. The authors indicated how network interactions shape SBM changes. Yet, such changes result in new partnerships and the positioning of different actors within the network.

Tolkamp et al. (2018) developed a user-centered approach to SBMs. Their case study is based on research of companies providing energy efficiency services in the Netherlands. This paper provides an in-depth analysis on user involvement in SBMs.

Johannsdottir and McInerney (2018) developed a framework, called "Five C", that can be used as a blueprint for SBM development by insurance copmanies. This paper took a strategic management approach, and argues that sustainability is of utmost imporance in the business model of insurance companies.

Ritala et al. (2018) studied the adoption of SBM archetypes in the S\&P 500 index using longitudinal data from secondary sources for the period 2005 to 2014. They noted that the main activities associated with sustainable value creation are related to material efficiency, waste management, and renewable energy efficiency.

Yip and Bocken (2018) studied SBM archetypes in the retail banking industry in Hong Kong. All eight of the SBM archetypes from the original work (Bocken et al., 2014) were found and validated. This paper provides further details on how banks approach the realization of these SBM archetypes, and concludes with a critical discussion on how to prepare a transition towards sustainable banking.

Palomares-Aguirre et al. (2018) focused on the scalability of SBMs for the benefit of the base of the pyramid. Their case study of three housing companies in Mexico reveals that community embeddedness and government support are essential for the success of these types of SBMs. They also argue that a reliance on market forces is insufficient to for scaling the impact and serving the most vulnerable communities of our societies.

\subsection{Topic 2: the technology-centered approach to sustainable business models}

The second topical area of this volume is related to the technology-centered approach to SBMs (7 papers). This topic encompasses papers focused on sustainable and social manufacturing, circular business models, SBMs for waste management, and peer-to-peer platforms. These papers provide practical examples and tools that could be useful to practitioners developing SBMs, including circular models, in various industries such as waste management, clothing production, peer-to-peer sharing platforms, or ICT. They can also serve as inspiration for initiatives in other industries or for policy makers trying to foster SBM development in relation to new technologies. These papers provide a link between SBM and technology. The literature on business models has long tradition in explaining the rise in new business models due to technological advances of the last decades (Foss and Saebi, 2017), and this remains relevant also in the field of SBM. The papers assembled here are provide particularly valuable insights for managers and policy makers. Heys et al. (2018), for example, provide a new ontology for SBMs for small enterprises in ICT, and thus contribute to the current development of SBM ontologies (Breuer, 2013; Upward and Jones, 2016; Joyce and Paquin, 2016; Jonker, 2016). Piscicelli et al. (2018) contribute with the discussion of success, but also of failure in SBMs. Studying failure cases is of particular importance for the SBM field, as studying only success cases might introduce unintended bias for cumulative knowledge development. Yet, another important discussion in SBM literature is related to its organizational approach. In this discussion, Battilana and Dorado (2010) argue in favor of hybrid organization, blending sustainability and profit logics. Moreover, Schaltegger et al. (2016b) advance the so-called co-evolutionary approach, emphasising the importance of gradual evolution in the business models of companies in transition to sustainability. In this SV, the paper of Stål and Corvellec (2018) contribute with a decouling approach to SBM, arguing that internal and external organizational structure and separation of processes can contribute to sustainability practice. Each paper's main ideas are presented below.

Caldera et al. (2017) provided a detailed overview of lean and green models in sustainable manufacturing. These models encompass best practices in manufacturing streams such as waste, energy, emissions, water and chemical management. The authors presented eighteen integrated methods for environmental treatment of the above-mentioned work streams. Based on their synthesis of the literature, the reader will find a useful overview of how integrated management methods can be adopted in SBMs, combining lean management with sustainability.

Hirscher et al. (2018) contributed to the discussion of multiple values in SBMs by developing a value framework based on an extensive study of social manufacturing in the fashion industry. They conducted twelve workshops with in-depth qualitative research comprising seventeen focus groups and a total of onehundred-and-one respondents. This research occurred in Finland and in the U.S., and discussed the need for SBMs to also get local level support.

Stål and Corvellec (2018) took a decoupling perspective on SBMs. The researchers studied seven Swedish apparel companies, and their adoption of a circular business model in the recycling of clothing. Their study is indicative that organizational structure in SBMs is important, and shows how outsourcing and internal separation can lead to strengthening of the SBM.

Heyes et al. (2018) have organized four workshops to unravel the drivers of the circular type of SBMs applicable in the ICT service industry. This paper presents key actions, barriers and elements of circular SBMs for ICT, following a business model canvas ontology. The authors contend that small (micro) enterprises can play a fundamental role in a circular economy.

Tong et al. (2018) presented a variety of business models for recycling waste of electric and electronic equipment in China. The authors have collected data through sixty-five interviews in the period 2005-2013, and through participation in what they call a social experiment, conducted in preparation of community based recycling programs. Fully in the spirit of this SV, Tong et al. (2018, p. 672 ) conclude that " $(. .$.$) there is not just one business model, but a$ variety of models to fit different institutional settings (...)".

Ribeiro et al. (2018) used life cycle assessment (LCA) to analyze the success factors in the Fruta Feia (Ugly Fruits) case in Portugal. In addition to the LCA, the authors used two complementary methods - social life cycle assessment and social return on investment - to provide the reader with an in-depth analysis of a case that successfully reduces food waste.

Piscicelli et al. (2018) made a comparative study of a successful and unsuccessful peer-to-peer sharing platform. Their case study 
approach was complemented with the Schwartz Portrait Value Questionnaire that was administered to more than one-thousand users of each case. The authors found similarities in the personality traits of the users, and hence attribute the success or failure of the cases to the differences in the business model adopted in each platform.

\subsection{Topic 3: the entrepreneurship and innovation based approaches to sustainable business models}

The third topical area of this volume is related to entrepreneurship and innovation-based approaches to SBMs (13 papers). It encompasses papers on, sustainable entrepreneurship, innovations and social entrepreneurship. While discussions on SBMs from the perspective of sustainable entrepreneurship and innovation are common (Schaltegger and Wagner, 2011; Boons and LüdekeFreund, 2013; Evans et al., 2017), the link between SBMs and social entrepreneurship a logical but novel extension. The very definition of social entrepreneurship illustrates the logic of extending SBM studies towards social entrepreneurship. Dees (1998, p. 4) argued already in his early work that "Social entrepreneurs play the role of change agents in the social sector, by [...] engaging in a process of continuous innovation, adaptation, and learning; acting boldly without being limited by resources currently at hand [...]". This SV offers a literature review on social entrepreurship (Macke et al., 2018) and insights on the potential influence of social entrepreneurs on industry-wide dynamics through the introduction of innovative SBM (Olofsson et al., 2018). Other studies making the link between social entrepreneurship and SBM are of more practical nature, and provide specific recommendations about resource mobilization, scaling, internationalization and resolving strong tensions (Davies and Chambers, 2018; Dobson et al., 2018; McDermott et al., 2018). Another important topic for SBM scholarship can be borrowed from social entrepreneurship, viz. Mission drift or giving priority to financial results as opposed to social mission (Ebraham et al., 2014). In this SV, Siegner et al. (2018) delve into how companies can sustain the social mission as part of their SBMs. Of course, the papers relating to the more conventional sustainable entrepreneurship and innovations in SBMs have also valuable insights, summarized in the individual presentation of papers below. The linchpin of all papers in this topical area is related to examining the opportunity development process in new firms, often based on innovative initiatives, that might lead to success, but also often result in entrepreneurs having to resolve numerous challenges along the way. Each paper's main ideas are summarized below.

Dobson et al. (2018) studied the scaling and internationalization of a social enterprise called ViaVia Travellers Café. The authors stressed the fact that SBMs expand in the context of uncertainty, and thus contextual studies of SBMs are absolutely required. They argued that, under uncertainty, it is not necessary to have a proven SBM before scaling it up. A more iterative process of developing and scaling up the business model is thus recommended.

Siegner et al. (2018) discussed the tensions that may arise in an SBM itself. They used a hybrid organizational lens to study these tensions in a German social entrepreneurship context. One of their main messages referred to the possibility of developing the socalled social mission design tension, to prevent sustainability principles being forgotten in business models.

Olofsson et al. (2018) studied the impact of social enterprises in the Scandinavian electricity retail market. Based on a case study with sixteen interviews and two focus groups, the authors asserted that business model innovation of social entrepreneurs can have a major impact on the traditional business models in the sector, and therefore drives the entire sector towards sustainability.
McDermott et al. (2018) studied the resource mobilization of social enterprises that are active in convening cross-sector partnerships. Based on their qualitative research, the authors demonstrated how SBMs can realize opportunities (recognition, discovery and creation), and mobilize resources without any expectation of financial reciprocity.

Macke et al. (2018) presented a literature review on the topic of social entrepreneurship. They identified three clusters of topics that have impact on the SBMs of social entreprises, i.e. (i) social inclusion and social economy, (ii) economic development, (iii) networks and social innovation.

Neumeyer and Santos (2018) compared the network connectivity of sustainable and conventional entrepreneurs. They studied two municipal entrepreneurial ecosystems in the U.S. based on 90 face-to-face interviews. Although sustainable entrepreneurs were underrepresented in both ecosystems, their networks appeared to be more densely connected in comparison to conventional entrepreneurial networks.

Täuscher and Abdelkafi (2018) contributed to the design school of SBMs. They developed a simulation for the scalability and robustness of an entrepreneurial venture - Coursera - which has a social mission to make education globally accessible. Their simulation presented a considerable number of promising opportunities for the future development of the SBM field, since it models the robustness and success of various settings (i.e. complex, dynamic and interdependent).

Kokkonen and Ojanen (2018) studied bioenergy entrepreneurship in Finland. Taking the lens of the Theory of Planned Behavior and the Technology Acceptance Model, the authors proposed an integrated model for the realization of SBM opportunities, and successful incorporation into small businesses.

Davies and Chambers (2018) have also used a hybrid organization lens to study the tensions experienced by sustainability entrepreneurs. Based on a case study of ten social entrepreneurs and twenty-one interviews, the authors present an overview of SBM tensions as well as business model innovations that can mitigate these tensions.

Kozlowski et al. (2018) reviewed various sustainable entrepreneurship practices in the fashion industry. They identified gaps, and subsequently develop an ontology for the creation of SBMs in fashion. The proposed "reDesign Canvas" consists of twelve building blocks, and aims at supporting the development of more sustainable outcomes in the fashion industry.

Chen et al. (2018) adopted a comparative study of factors for crowdfunding of sustainability entrepreneurs. Their research is based on sixty-three cases twenty-five from the U.S and thirtyeight from China. Using a system dynamics lens, the authors visualize the dynamic process of crowdfunding, and assert that public opinion, brand effect and government policies can enhance the effectiveness of crowdfunding for sustainability focused enterprises.

Oskam et al. (2018) examined sustainable innovations from a network theory perspective. Based on case study research, they advanced the concept of value shaping through networking as a process that improves SBM outcomes.

Fellnhofer (2017) contended that Stevenson's (1983) multilevel approach to entrepreneurial management is beneficial for predicting the success of sustainability innovations. The author analysed data coming from three-hundred-and-one online surveys with employees from four sectors, i.e. ICT, construction, transportation and aircraft part supplier. The study revealed the interplay of factors at the individual, working group and firm level that help explain the success of sustainable business model innovations. These factors include resource orientation, management orientation, strategic orientation, growth orientation, reward philosophy 
and entrepreneurial culture, and thus proposes to use them as predictive indicators of SBM success.

\subsection{Topic 4: the behavioral approach to sustainable business models}

Last but not least, the fourth and final topical area of this volume takes a behavioral approach to SBMs. It embraces six papers related to the management of pro-environmental behavior, of sustainability change and transformation, and of implementing formal management systems. A behavioral perspective on SBMs has the potential to provide novel insights in the field, since at the core of each business model is the motivation of each stakeholder to contribute (Magretta, 2002). In this line of reasoning, papers from this topical area are focused either on the individual level of analysis, examining behavior of individual employees or managers (e.g., Maletič et al., 2018; Wesselink et al., 2017), or on the firm level of analysis (e.g., Long et al., 2018). Leadership is another important topic in sustainability (Fullan, 2005; Brown et al., 2005), which however is not well embedded in SBM scholarship. Wesselink et al. (2017) suggest that leadership matters in pro-environmental behavior, and can play an important role in SBM. Moreover, also in this topical area the need for government support is empasized by Plank and Teichmann (2018). In other words, governments can play an important role in the motivation of various stakeholders to engage in SBMs. This relates to discussions on governance and regulations in support of sustainability (Albareda et al., 2008; Lepoutre et al., 2007; Steurer, 2010). On another note, this SV presents a case of withdrawal from environmental management practices (Merli and Preziosi, 2018). Again, failure studies are at the current frontier of SBM research, and more of these are needed to learn from both successes and failures in SBM management. Paper summaries follow below.

Wesselink et al. (2017) studied the pro-environmental behavior of individual employees, by using the Theory of Planned Behavior. They found that the exemplary behavior of leaders and perceived organizational support lead to both the intention and the actual pro-environmental behavior of employees. Their conclusions were based on data gathered from an online survey administered with five-hundred-and-forty employees across four housing associations in the Netherlands. Since individual motivations are the cornerstone of (sustainable) business models (Magretta, 2002), the results of this study are useful in highlighting the value of the behavioral approach.

Plank and Teichmann (2018) employed an information asymmetry lens to study social and environmental behavior. Their study is composed of a mixed model of qualitative research (pre-study) and experiment on Corporate Social and Environmental Behavior (CSEB facts Panel). They argued that the CSEB facts panel is a way that companies differentiate in adopting SBMs, and that government involvement can help accelerate the adoption of SBMs.

Scarpellini et al. (2017) studied the change management process and its impact on SBM evolution and realization. Their study was based on the pro-environmental behavior of three-hundred-andthree Spanish firms. Their study suggested that the transformation of firm's activities toward a SBM is a systematic process of adopting pro-environmental practices.

Maletič et al. (2018) used a contingency lens to review sustainability practices and organizational performance. Based on a survey with two-hundred-and-forty-seven middle and senior managers from European organizations, the authors concluded that organizations with similar characteristics may develop differently, and customize SBMs.

Long et al. (2018) used a change management lens to review the transformation from traditional business models to SBMs. Based on fourteen cases of SMEs in the Dutch food and beverage industry, they discuss both key success factors and the main barriers for realizing the transformation toward SBMs. They argued that making sustainability the heart of business philosophy is amongst the most important success factors for realizing the transition.

Merli and Preziosi (2018) studied the factors that influence Italian firms to withdraw from a formal management system such as EMAS (eco-management and audit scheme). Formal management systems are in principle supportive and strengthening of SBMs. Based on a survey with respondents from five-hundred-andsixty-two Italian companies, the researchers, however, present a detailed overview of the reasons for withdrawal from these environmental management systems.

\section{Avenues for future research in the field of sustainable business models}

Synthesizing the existing insights from prior research and the newly developed knowledge from this volume, in the following six avenues for future research in the SBM field - based on the editors' reading of the literature - are presented:

i) A more robust conceptualization of sustainability and SBMs;

ii) Stronger and more cumulative theoretical development concerning the antecedents, processes, and outcomes of SBMs;

iii) More sophisticated and rigorous empirical methods to investigate SBMs;

iv) Regularly including and studying the role of government and the related institutional arrangements for the development, diffusion, and success of SBM across different national and regional contexts;

v) Examining in more depth the interactions between existing business models and SBMs in one sector or even one company;

vi) Creating dialogue and intersection with other research communities, such as "traditional" business model researchers, innovation scholars, or the entrepreneurship community.

First, while there has been a lot of focus on the theoretical clarification of the concept of SBM (Lüdeke-Freund and Dembek, 2017), it still remains somewhat ambiguous, resulting in many different interpretations and applications across different contextual settings. This is not surprising given that the original concept of business models is still relatively young; scholars have debated for several years the definition of a business model (Zott et al., 2011; Massa et al., 2017) or business model innovation more recently (Foss and Saebi, 2017). The extension of the business model conceptualization to the field of sustainable business models therefore remains in its early stages of development. Whilst there is a general agreement that SBM researchers should embrace the idea of sustainable development, the operationalization of sustainability-related concepts remains challenging since the "value" inherent in SBMs is subject to debate going beyond value (creation) as expressed in economic terms only (e.g., Stubbs and Cocklin, 2008). Economic value remains easier to evaluate and measure, for instance through the examination of the company's financial and accounting reports, as compared to social or environmental value created by SBMs, which is much harder to objectively evaluate or express in financial terms. As studies included in this SV demonstrate (Table 2), the majority of research efforts have focused on studying cases, which is useful to establish basic vocabulary, tensions, and challenges involving SBMs, but this research design prevents finding generalizability to different industries, 
contexts, or countries.

Second, further addressing SBM antecedents, processes, and outcomes could be facilitated by stronger and more cumulative theories. The prolific field of research on SBMs could further flourish based on more sophisticated theoretical contributions. Although some papers in this SV referred to an explicit theoretical lens, too many papers in the SBM field remain mainly descriptive. For the further development of the field from its early stages focused on description into maturity focused on in-depth analysis and maybe even prescription, it is important to embed contributions in formal theories, including a theoretical contribution in published papers (Corley and Gioia, 2011), and suggesting testable propositions based on theory-inspired models (Whetten, 1989). This SV demonstrates a variety of theoretical perspectives authors have taken to study SBMs (i.e., Table 1). This variety is, however, a double-edged sword. It provides a wellspring of ideas and novel tools and methods, but it also prevents cumulative knowledge development and testing, needed to provide more practical solutions for practitioners that are faced with solving pressing sustainability challenges. Further contributions to the development of a more cumulative theory for studying SBMs and advising practitioners and politicians concerning SBMs is considered a necessity.

Third, and related to the previous, more sophisticated and rigorous methods will be necessary for the further development of the field. Experiments, simulations, and surveys could represent the future of SBM research, since these research methods make it possible to test a variety of variables and provide more grounds for causal explanations, especially in cases of experiments and simulations. In addition to quantitative methods, a mixed-method approach involving qualitative and quantitative evaluations is recommended, since context is quite important for the understanding of SBMs. Multiple perspectives in terms of inter-, transdisciplinary, and systemic approaches, some of which are also highlighted in this SV, might be helpful in this endeavor and should be nurtured further.

Fourth, the varying contextual settings do not only refer to cultural contexts, industrial sectors, or types of organizations (like for-profit and not-for-profit ones), but also to the level of analysis at which the SBMs are studied. Level of analysis can be situated at the individual, team, organizational, inter-organizational, regional, national, or multinational level (Lenssen et al., 2014). This brings the role of governments and various governance mechanisms to the fore, often important for encouraging the development of SBMs (Gond et al., 2011; Knudsen et al., 2013; Dentchev et al., 2017). Without government regulation, the social and environmental impact of SBMs is endangered to remain underdeveloped in many settings. Although a couple of papers in this volume have started to address the crucial role of government for SBMs (e.g., Chen et al., 2018; Plank and Teichmann, 2018; Osborne et al., 2014), more research is needed at the intersection of political preoccupations and the development and trajectories of SBMs across different institutional regimes to examine potential convergence, but also divergence of paths to sustainability in different countries and regions, including European Union, North America, Africa, Asia, and Oceania.

Fifth, the complex and dynamic "reality" is often neglected and simplified by describing one single business model without acknowledging links, overlaps, synergies and the co-existence of various (S)BMs (Snihur and Tarzijan, 2018). Further considerations of interactions between existing business models in established firms, and the impact of new, sustainable business models could be productively studied in the future in particular industries or even in single companies. For instance, can existing firms add sustainable business models to their business model portfolio? What are the outcomes and process characteristics of such initiatives? Can entrepreneurs introducing SBMs serve as role models to influence existing business practices and accelerate the path to more sustainable development? These interactions between existing business models and SBMs are particularly important as innovation research suggests that hybridization practices might help organizations learn during times of transition to improve future performance (Furr and Snow, 2015). Thus, existing organizations adopting entirely new SBMs or some of the new practices might prove to be the needed stepping-stones for the transition to a more sustainable economic and social organization of our society. More research is required to shed light on these issues.

Sixth, and in line with the original reasons for this SV, evidence is abundant that the productive continuation of research in this prolific field will only be feasible if further synergies with other research streams and communities are created and sustained. Research related to "traditional" business model literature (e.g., Zott et al., 2011), innovation community that has embraced research on business model innovation (e.g., Foss and Saebi, 2017), or entrepreneurship community interested in topics related to the opportunity development processes that often include business model considerations (Selden and Fletcher, 2015; Snihur et al., 2017) to name but a few, might throw light upon challenges arising in the field of SBMs as well as benefit from the insights generated in the nascent field of SBM research. Moreover, this could result in promising and constructive dialogues and intersections in sustainability research, which in principle are interdisciplinary by nature given the complexity of the problems currently faced by our society.

\section{Conclusions}

The study of sustainable business models constitutes a prolific field of research, practice, and policy preoccupations. This SV presents 37 papers from around the world and across various industries examining the core issues and questions pertaining to SBM generation, development, and management. We posit that there exists a great potential for multidisciplinary research to build on during the next decades with the objective to surpass the current understanding of SBMs. Exploring this novel research area more deeply offers great opportunities for multi-method and multidisciplinary contributions, novel data sources, and innovative methods and tools, already sketched in this SV, yet awaiting further leaps forward.

\section{Acknowledgements}

We are grateful to Don Huisingh for his vision and support in developing this SV. While most journals would prefer acceptance of limited number of papers, Don has encouraged us to really "embrace the variety of sustainable business models". Special thanks go also to Yutao Wang (responsible for this SV) for his guidance, and to Jiří Jaromír Klemeš and Cecília Maria Villas Bôas de Almeida, the three editors-in-chief of the journal. We are grateful to Karthik Kumar and Jia Yang from Elsevier, who patiently and kindly supported us in the production of this SV. We are also very thankful to the anonymous reviewers, whose comments were very much appreciated and helpful in the development of the ideas presented in many of these papers. Credit for the quality of this SV is of course given to the authors of this SV, whose contribution expands our knowledge in the field.

\section{References}

Albareda, L., Lozano, J.M., Tencati, A., Midttun, A., Perrini, F., 2008. The changing role of governments in corporate social responsibility: drivers and responses. Bus. 
Ethics Eur. Rev. 17 (4), 347-363.

Albareda, L., Lozano, J.M., Ysa, T., 2007. Public policies on corporate social responsability: the role of governments in Europe. J. Bus. Ethics 43 (74), $391-407$.

Arevalo, J.A., Castelló, I., Colle, S.D., Lenssen, G., Neumann, K., Zollo, M., 2011. Introduction to the special issue: integrating sustainability in business models. J. Manag. Dev. 30 (10), 941-954.

Bansal, P., 2003. From issues to actions: the importance of individual concerns and organizational values in responding to natural environmental issues. Organ. Sci. 14 (5), 510-527.

Battilana, J., Dorado, S., 2010. Building sustainable hybrid organizations: the case of commercial microfinance organizations. Acad. Manag. J. 53 (6), 1419-1440.

Bidmon, C.M., Knab, S.F., 2018. The three roles of business models in societal transitions: new linkages between business model and transition research. J. Clean. Prod. 178, 903-916.

Bocken, N.M.P., Short, S.W., Rana, P., Evans, S., 2014. A literature and practice review to develop sustainable business model archetypes. J. Clean. Prod. 65, 42-56.

Boons, F., Lüdeke-Freund, F., 2013. Business models for sustainable innovation: state-of-the-art and steps towards a research agenda. J. Clean. Prod. 45, 9-19.

Boons, F., Montalvo, C., Quist, J., Wagner, M., 2013. Sustainable innovation, business models and economic performance: an overview. J. Clean. Prod. 45, 1-8.

Brehmer, M., Podoynitsyna, K., Langerak, F., 2018. Sustainable business models as boundary-spanning systems of value transfers. J. Clean. Prod. 172, 4514-4531.

Breuer, H., 2013. Lean venturing: learning to create new business through exploration, elaboration, evaluation, experimentation, and evolution. Int. J. Innov. Manag. 17, 22. Article 1340013.

Brown, M.E., Treviño, L.K., Harrison, D.A., 2005. Ethical leadership: a social learning perspective for construct development and testing. Organ. Behav. Hum. Decis. Process. 97 (2), 117-134.

Brundtland, G.H., 1987. Our Common Future: Report of the World Commission on Environment and Development. University Press, Oxford.

Caldera, H.T.S., Desha, C., Dawes, L., 2017. Exploring the role of lean thinking in sustainable business practice: a systematic literature review. J. Clean. Prod. 167, $1546-1565$.

Carroll, A.B., 1979. A three-dimensional conceptual model of corporate performance. Acad. Manag. Rev. 497-505.

Chen, J., Chen, L., Chen, J., Xie, K., 2018. Mechanism and policy combination of technical sustainable entrepreneurship crowdfunding in China: a system dynamics analysis. J. Clean. Prod. 177, 610-620.

Corley, K.G., Gioia, D.A., 2011. Building theory about theory: what constitutes a theoretical contribution? Acad. Manag. Rev. 36 (1), 12-32.

Davies, I.A., Chambers, L., 2018. Integrating hybridity and business model theory in sustainable entrepreneurship. J. Clean. Prod. 177, 378-386.

Dees, J.G., 1998. The Meaning of "Social Entrepreneurship." Stanford University - graduate School of Business, pp. 1-5.

Dentchev, N.A., Haezendonck, E., van Balen, M., 2017. The role of governments in the business and society debate. Bus. Soc. 56 (4), 527-544.

Dentchev, N., Baumgartner, R., Dieleman, H., Jóhannsdóttir, L., Jonker, J., Nyberg, T., Rauter, R., Rosano, M., Snihur, Y., Tang, X., van Hoof, B., 2016. Embracing the variety of sustainable business models: social entrepreneurship, corporate intrapreneurship, creativity, innovation, and other approaches to sustainability challenges. J. Clean. Prod. 113 (1), 1-4.

Dobson, K., Boone, S., Andries, P., Daou, A., 2018. Successfully creating and scaling a sustainable social enterprise model under uncertainty: the case of ViaVia Travellers Cafés. J. Clean. Prod. 172, 4555-4564.

Ebrahim, A., Battilana, J., Mair, J., 2014. The governance of social enterprises: mission drift and accountability challenges in hybrid organizations. Res. Organ.Behav. 34, 81-100.

Eisenhardt, K.M., Graebner, M.E., Sonenshein, S., 2016. Grand challenges and inductive methods: rigor without rigor mortis. Acad. Manag. J. 59 (4), 1113-1123.

Evans, S., Vladimirova, D., Holgado, M., Van Fossen, K., Yang, M., Silva, A., Barlow, C.Y., 2017. Business model innovation for sustainability: towards a unified perspective for creation of sustainable business models. Bus. Strat. Environ. 26 (5), 597-608.

Fellnhofer, K., 2017. Drivers of innovation success in sustainable businesses. J. Clean. Prod. 167, 1534-1545.

Foss, N.J., Saebi, T., 2017. Fifteen years of research on business model innovation: how far have we come, and where should we go? J. Manag. 43 (1), 200-227.

Fullan, M., 2005. Leadership \& Sustainability: System Thinkers in Action. Corwin Press.

Furr, N., Snow, D., 2015. Inter-generational hybrids: spillbacks, spillforwards, and surviving technological discontinuities. Organ. Sci. 6 (2), 475-493.

Gallo, P.J., Antolin-Lopez, R., Montiel, I., 2018. Associative sustainable business models: cases in the bean-to-bar chocolate industry. J. Clean. Prod. 174, 905-916.

Gond, J.P., Kang, N., Moon, J., 2011. The government of self-regulation: on the comparative dynamics of corporate social responsibility. Econ. Soc. 40 (4), $640-671$.

Haigh, N., Walker, J., Bacq, S., Kickul, J., 2015. Hybrid organizations: origins, strategies, impacts, and implications. Calif. Manag. Rev. 57 (3), 5-12.

Heyes, G., Sharmina, M., Mendoza, J.M.F., Gallego-Schmid, A., Azapagic, A., 2018. Developing and implementing circular economy business models in serviceoriented technology companies. J. Clean. Prod. 177, 621-632.

Hirscher, A.-L., Niinimäki, K., Joyner Armstrong, C.M., 2018. Social manufacturing in the fashion sector: new value creation through alternative design strategies? J. Clean. Prod. 172, 4544-4554.

Johannsdottir, L., McInerney, C., 2018. Developing and using a Five C framework for implementing environmental sustainability strategies: a case study of Nordic insurers. J. Clean. Prod. 183 (10), 1252-1263.

New business models. In: Jonker, J. (Ed.), 2016. Working Together on Value Creation. Stichting OCF2.0 Foundation, Doetinchem, The Netherlands.

Joyce, A., Paquin, R.L., 2016. The triple layered business model canvas: A tool to design more sustainable business models. J. Clean. Prod. 135, 1474-1486.

Karlusch, A., Sachsenhofer, W., Reinsberger, K., 2018. Educating for the development of sustainable business models: designing and delivering a course to foster creativity. J. Clean. Prod. 179, 169-179.

Knudsen, J.S., Moon, J., Slager, R., 2013. Government policies for corporate social responsibility in Europe: a comparative analysis of institutionalisation. Pol. Polit. 1-19.

Kolk, A., Rivera-Santos, M., Rufin, C., 2014. Reviewing a decade of research on the "Base/Bottom of the pyramid" (BOP) concept. Bus. Soc. 53 (3), 338-377.

Kokkonen, K., Ojanen, V., 2018. From opportunities to action - an integrated model of small actors' engagement in bioenergy business. J. Clean. Prod. 182, 496-508.

Kozlowski, A., Searcy, C., Bardecki, M., 2018. The reDesign Canvas: fashion design as a tool for sustainability. J. Clean. Prod. 183, 194-207.

Lenssen, J.-J., Dentchev, N.A., Roger, L., 2014. Sustainability, Risk management and governance: towards an integrative approach. Corp. Gov. Internat. J. Bus. Soc. 14 (5), 670-684.

Lepoutre, J., Dentchev, N.A., Heene, A., 2007. Dealing with uncertainties when governing CSR policies. J. Bus. Ethics 73 (4), 391-408.

Long, T.B., Looijen, A., Blok, V., 2018. Critical success factors for the transition to business models for sustainability in the food and beverage industry in The Netherlands. J. Clean. Prod. 175, 82-95.

Lüdeke-Freund, F., Dembek, K., 2017. Sustainable business model research and practice: emerging field or passing fancy? J. Clean. Prod. 168, 1668-1678.

Macke, J., Sarate, J.A.R., Domeneghini, J., da Silva, K.A., 2018. Where do we go from now? Research framework for social entrepreneurship. J. Clean. Prod. 183, 677-685.

Magretta, J., 2002. Why business models matter. Harv. Bus. Rev. 80 (5), 86-92.

Maletič, M., Maletič, D., Gomišček, B., 2018. The role of contingency factors on the relationship between sustainability practices and organizational performance. J. Clean. Prod. 171, 423-433.

Massa, L., Tucci, C., Afuah, A., 2017. A critical assessment of business model research. Acad. Manag. Ann. 11 (1), 73-104.

McDermott, K., Kurucz, E.C., Colbert, B.A., 2018. Social entrepreneurial opportunity and active stakeholder participation: resource mobilization in enterprising conveners of cross-sector social partnerships. J. Clean. Prod. 183, 121-131.

Merli, R., Preziosi, M., 2018. The EMAS impasse: factors influencing Italian organizations to withdraw or renew the registration. J. Clean. Prod. 172, 4532-4543.

Neumeyer, X., Santos, S.C., 2018. Sustainable business models, venture typologies, and entrepreneurial ecosystems: a social network perspective. J. Clean. Prod. 172, 4565-4579.

Olofsson, S., Hoveskog, M., Halila, F., 2018. Journey and impact of business model innovation: the case of a social enterprise in the Scandinavian electricity retail market. J. Clean. Prod. 175, 70-81.

Osborne, S.P., Radnor, Z., Vidal, I., Kinder, T., 2014. A sustainable business model for public service organizations? Publ. Manag. Rev. 16 (2), 165-172.

Oskam, I., Bossink, B., de Man, A.-P., 2018. The interaction between network ties and business modeling: case studies of sustainability-oriented innovations. J. Clean. Prod. 177, 555-566.

Osterwalder, A., Pigneur, Y., 2010. Business Model Generation: a Handbook for Visionaries, Game Changers, and Challengers. Wiley \& Sons, Hoboken, NJ.

Palomares-Aguirre, I., Barnett, M., Layrisse, F., Husted, B.W., 2018. Built to scale? How sustainable business models can better serve the base of the pyramid. J. Clean. Prod. 172, 4506-4513.

Piscicelli, L., Ludden, G.D.S., Cooper, T., 2018. What makes a sustainable business model successful? An empirical comparison of two peer-to-peer goods-sharing platforms. J. Clean. Prod. 172, 4580-4591.

Plank, A., Teichmann, K., 2018. A facts panel on corporate social and environmental behavior: decreasing information asymmetries between producers and consumers through product labeling. J. Clean. Prod. 177, 868-877.

Prahalad, C., Hart, S., 1999. Strategies for the Bottom of the Pyramid. creating sustainable development, Ann Arbor, pp. 1-26.

Ribeiro, I., Sobral, P., Peças, P., Henriques, E., 2018. A sustainable business model to fight food waste. J. Clean. Prod. 177, 262-275.

Ritala, P., Huotari, P., Bocken, N., Albareda, L., Puumalainen, K., 2018. Sustainable business model adoption among S\&P 500 firms: a longitudinal content analysis study. J. Clean. Prod. 170, 216-226.

Rossignoli, F., Lionzo, A., 2018. Network impact on business models for sustainability: case study in the energy sector. J. Clean. Prod. 182, 694-704.

Scandura, T.A., Williams, E.A., 2000. Research methodology in management: current practices, trends and implications for future research. Acad. Manag. J. 43 (6), $1248-1264$.

Scarpellini, S., Valero-Gil, J., Rivera-Torres, P., Garcés-Ayerbe, C., 2017. Analysis of the generation of economic results in the different phases of the pro-environmental change process. J. Clean. Prod. 168, 1473-1481.

Schaltegger, S., Hansen, E.G., Lüdeke-Freund, F., 2016a. Business models for sustainability: origins, present research, and future avenues. Organ. Environ. 29 (1), $3-10$. 
Schaltegger, S., Lüdeke-Freund, F., Hansen, E.G., 2016b. Business models for sustainability: a Co-Evolutionary analysis of sustainable entrepreneurship, innovation, and transformation. Organ. Environ. 29 (3), 264-289.

Schaltegger, S., Wagner, M., 2011. Sustainable entrepreneurship and sustainability innovation: categories and interactions. Bus. Strat. Environ. 20, 222-237.

Selden, P.D., Fletcher, D.E., 2015. The entrepreneurial journey as an emergent hierarchical system of artifact-creating processes. J. Bus. Ventur. 30 (4), 603-615.

Siegner, M., Pinkse, J., Panwar, R., 2018. Managing tensions in a social enterprise: the complex balancing act to deliver a multi-faceted but coherent social mission. J. Clean. Prod. 174, 1314-1324.

Snihur, Y., Tarzijan, J., 2018. Managing complexity in a multi-business-model organization. Long. Range Plan. 51 (1), 50-63.

Snihur, Y., Reiche, B.S., Quintane, E., 2017. Sustaining actor engagement during the opportunity development process. Strateg. Entrep. J 11 (1), 1-17.

Stål, H.I., Corvellec, H., 2018. A decoupling perspective on circular business model implementation: illustrations from Swedish apparel. J. Clean. Prod. 171, 630-643.

Stevenson, H.H., 1983. A perspective on entrepreneurship. Harvard Business School Background Note 13,1-13.

Steurer, R., 2010. The role of governments in corporate social responsibility: characterising public policies on CSR in Europe. Pol. Sci. 43, 49-72.

Stubbs, W., Cocklin, C., 2008. Conceptualizing a "sustainability business model." organ. Environ. Times 21, 103-127.

Svensson, G., Wagner, B., 2011. Transformative business sustainability: multi-layer model and network of e-footprint sources. Eur. Bus. Rev. 23 (4), 334-352.

Täuscher, K., Abdelkafi, N., 2018. Scalability and robustness of business models for sustainability: a simulation experiment. J. Clean. Prod. 170, 654-664.

Tolkamp, J., Huijben, J.C.C.M., Mourik, R.M., Verbong, G.P.J., Bouwknegt, R., 2018. User-Centred sustainable business model design: the case of energy efficiency services in The Netherlands. J. Clean. Prod. 182, 755-764.

Tong, X., Tao, D., Lifset, R., 2018. Varieties of business models for post-consumer recycling in China. J. Clean. Prod. 170, 665-673.

Upward, A., Jones, P., 2016. An ontology for strongly sustainable business models: defining an enterprise framework compatible with natural and social science. Org. Environ. 29 (1), 97-123.

Wesselink, R., Blok, V., Ringersma, J., 2017. Pro-environmental behaviour in the workplace and the role of managers and organisation. J. Clean. Prod. 168, 1679-1687.

Whetten, D.A., 1989. What constitutes a theoretical contribution? Acad. Manag. Rev. 14 (4), 490-495.

Yip, A.W.H., Bocken, N.M.P., 2018. Sustainable business model archetypes for the banking industry. J. Clean. Prod. 174, 150-169.

Zott, C., Amit, R., Massa, L., 2011. The business model: recent developments and future research. J. Manag. 37 (4), 1019-1042. 